\title{
Study by modeling and simulation of open- switch fault diagnosis for five-level converters
}

\author{
Florent Becker, Ehsan Jamshidpour, Philippe Poure, and Shahrokh Saadate
}

\begin{abstract}
In this paper, an open-switch fault diagnosis method for five-level H-Bridge Neutral Point Piloted (HB-NPP) or T-type converters is proposed. While fault tolerant operation is based on three steps (fault detection, fault localization and system reconfiguration), a fast fault diagnosis, including both fault detection and localization, is mandatory to make a suitable response to an open-circuit fault in one of the switches of the converter. Furthermore, fault diagnosis is necessary in embedded and safety critical applications, to prevent further damage and perform continuity of service.

In this paper, we present an open-switch fault diagnosis method, based on the switches control orders and the observation of the converter output voltage level. In five-level converters such as HB-NPP and T-type topologies, some switches are mostly 'on' at the same time. Therefore, the fault localization is quite complicated. The fault diagnosis method we proposed is capable to detect and localize an open-switch fault in all cases. Computer simulations are carried out by using Matlab Simulink and SimPowerSystem toolbox to validate the proposed approach.
\end{abstract}

Index Terms - Open-switch fault; fault diagnosis; fault detection; fault localization; Multilevel converter; Neutral Point Piloted converter; T-type converter; H-bridge.

\section{INTRODUCTION}

Tn the recent decades, the high-power and Medium-Voltage I(MV) industrial applications have increased significantly. MV grids connection of these applications with respect of device rating limits requires some series-parallel combinations of power semiconductor switches. The Multilevel Converter (MC) topologies could provide significant advantages for these applications, such as output waveforms improvement and low switching frequency. Therefore, in a MC, the output filters and the use of passive components could be reduced. On the other hand, a low switching frequency allows performing high efficiency. Among the different $\mathrm{MC}$ topologies, the Neutral Point Piloted (NPP) converter is one of the widely used in high-power industrial applications, more

F. Becker and P. Poure, Institut Jean Lamour (UMR7198) University of Lorraine, Vandoeuvre les Nancy, France (email: florent.becker@univlorraine.fr ; philippe.poure@univ-lorraine.fr )

F. Becker and S .Saadate, GREEN laboratory University of Lorraine, Vandoeuvre les Nancy, France (email: shahrokh.saadate@univ-lorraine.fr )

E. Jamsidpour, Icube (UMR 7357) Université of Strasbourg, Illkirch, France and ECAM Strasbourg-Europe, Schiltigheim, France (email: Ehsan.JAMSHIDPOUR@ecam-strasbourg.eu) particularly in High Voltage-Direct Current transmission as well as in power quality improvement of PV generation and wind energy systems [1].

A combination of the NPP and H-Bridge topologies (HBNPP) that is depicted in Fig. 1 allows generating five voltage levels $\left(\mathrm{V}_{\mathrm{dc}}, \mathrm{V}_{\mathrm{dc}} / 2,0,-\mathrm{V}_{\mathrm{dc}} / 2,-\mathrm{V}_{\mathrm{dc}}\right)$. The five voltage levels are summarized in Table I with their associated switching states, considering the current $\mathrm{i}(\mathrm{t})$ direction. The Table I details the passing components associated to each voltage level for $\mathrm{i}(\mathrm{t})>0$. By the same, Table II is dedicated to $\mathrm{i}(\mathrm{t})<0$. The derived HBT-type topology (Fig. 2) allows generating the same voltage levels.

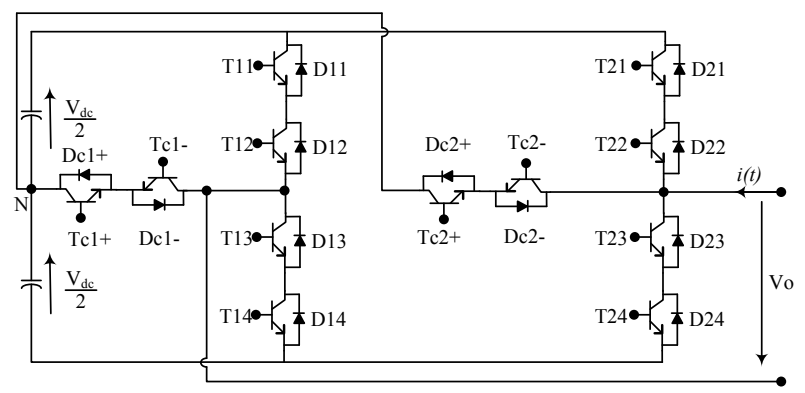

Fig. 1 HB-NPP five level topology.

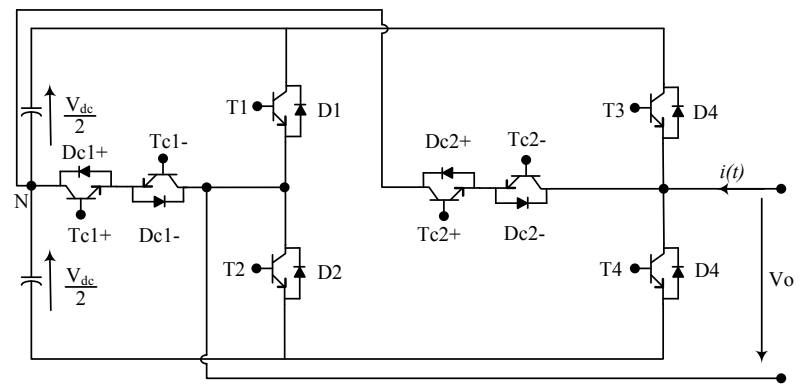

Fig. 2 HB-T-type five level topology.

TABLE I

VOLTAGE LEVELS AND POSSIBLE CORRESPONDING STATES FOR THE HB-NPP AND T-TYPE TOPOLOGIES FOR $\mathrm{i}(\mathrm{t})>0$.

\begin{tabular}{|c|c|c|c|}
\hline \multirow{2}{*}{$\begin{array}{c}\text { Voltage } \\
\text { level }\end{array}$} & \multirow{2}{*}{ State } & \multicolumn{2}{|c|}{ Passing components } \\
\cline { 3 - 4 } & & HB-NPP & T-Type \\
\hline \multirow{2}{*}{$\mathrm{V}_{\mathrm{dc}}$} & 1 & $\mathrm{~T} 11, \mathrm{~T} 12, \mathrm{~T} 23, \mathrm{~T} 24$ & $\mathrm{~T} 1, \mathrm{~T} 4$ \\
\hline \multirow{2}{*}{$\mathrm{V}_{\mathrm{dc}} / 2$} & 2 & $\mathrm{TC} 1+, \mathrm{DC} 1-, \mathrm{T} 23, \mathrm{~T} 24$ & $\mathrm{TC1}+, \mathrm{DC} 1-, \mathrm{T} 4$ \\
\cline { 2 - 4 } & 3 & $\mathrm{~T} 11, \mathrm{~T} 12, \mathrm{TC} 2-, \mathrm{DC} 2+-$ & $\mathrm{T} 1, \mathrm{TC} 2-, \mathrm{DC} 2+$ \\
\hline \multirow{3}{*}{0} & 4 & $\mathrm{TC} 1+, \mathrm{DC} 1-, \mathrm{TC} 2-, \mathrm{DC} 2+$ & $\mathrm{TC} 1+, \mathrm{DC} 1-, \mathrm{TC} 2-, \mathrm{DC} 2+$ \\
\cline { 2 - 4 } & 5 & $\mathrm{~T} 11, \mathrm{~T} 12, \mathrm{D} 22, \mathrm{D} 21$ & $\mathrm{~T} 1, \mathrm{D} 3$ \\
\cline { 2 - 4 } & 6 & $\mathrm{D} 13, \mathrm{D} 14, \mathrm{~T} 23, \mathrm{~T} 24$ & $\mathrm{D} 2, \mathrm{~T} 4$ \\
\hline$-\mathrm{V}_{\mathrm{dc}} / 2$ & 7 & $\mathrm{D} 13, \mathrm{D} 14, \mathrm{TC} 2-, \mathrm{DC} 2+$ & $\mathrm{D} 2, \mathrm{TC} 2-, \mathrm{DC} 2+$ \\
\hline
\end{tabular}

OPEN 2 ACcess 


\begin{tabular}{|c|c|c|c|}
\hline & 8 & TC1+, DC1-, D21, D22 & TC1+, DC1-, D3 \\
\hline$-\mathrm{V}_{\mathrm{dc}}$ & 9 & D13, D14, D21, D22 & D2, D3 \\
\hline
\end{tabular}

When fault occurrence is considered, one of the most critical elements in power electronic converters are the semiconductor switches. Switches or gate drivers faults, resulting in open-circuit fault (OCF) or short-circuit fault (SCF), affect the power generation and may lead to its shutdown. More than $30 \%$ of malfunctions and breakdowns are reported to be due to power semiconductor failures [2].

TABLE II

VOLTAGE LEVELS AND POSSIBLE CORRESPONDING STATES FOR THE HB-NPP AND T-TYPE TOPOLOGIES FOR $\mathrm{i}(\mathrm{t})<0$

\begin{tabular}{|c|c|c|c|}
\hline \multirow{2}{*}{$\begin{array}{l}\text { Voltage } \\
\text { level }\end{array}$} & \multirow{2}{*}{ State } & \multicolumn{2}{|l|}{ Passing components } \\
\hline & & HB-NPP & T-Type \\
\hline $\mathrm{V}_{\mathrm{dc}}$ & 1 & D11, D12, D23, D24 & D1,D4 \\
\hline \multirow{2}{*}{$\mathrm{V}_{\mathrm{dc}} / 2$} & 2 & TC1-, DC1+, D23, D24 & $\mathrm{TC} 1+, \mathrm{DC} 1-, \mathrm{T} 4$ \\
\hline & 3 & D11, D12, TC2+, DC2-- & D1, TC2+, DC2- \\
\hline \multirow{3}{*}{0} & 4 & TC1-, DC1+, TC2+, DC2 & TC1-, DC1+, TC2+, DC2- \\
\hline & 5 & $\mathrm{D} 11, \mathrm{D} 12, \mathrm{~T} 21, \mathrm{~T} 22$ & D1, T3 \\
\hline & 6 & T13, T14, D23, D24 & $\mathrm{T} 2, \mathrm{D} 4$ \\
\hline \multirow{2}{*}{$\begin{array}{l}-\mathrm{V}_{\mathrm{dc}} \\
/ 2\end{array}$} & 7 & $\mathrm{~T} 13, \mathrm{~T} 14, \mathrm{TC} 2+, \mathrm{DC} 2-$ & $\mathrm{T} 2, \mathrm{TC} 2+, \mathrm{DC} 2-$ \\
\hline & 8 & TC1-, DC1+, T21, T22 & TC1-, DC1+, T3 \\
\hline$-V_{d c}$ & 9 & $\mathrm{~T} 13, \mathrm{~T} 14, \mathrm{~T} 21, \mathrm{~T} 22$ & $\mathrm{~T} 2, \mathrm{~T} 3$ \\
\hline
\end{tabular}

Typically, industrial gate drivers include SCF protection (resulting in OCF) but OCF detection must be diagnosed to accomplish fault tolerance and continuity of service. Therefore, a fast and robust OCF diagnosis is required. A few works have studied open-switch fault detection in H-bridge converter and Multilevel Matrix Converters [3-7]. After fault detection, the localization of the faulty switch is mandatory to manage the post-fault operation as proposed in [8-11].

In this paper, a new OCF detection method with faulty switch localization capability is proposed. It can be applied to both HB-NPP and T-type topologies as well. The principle of the proposed fault detection method is summarized and detailed in the next section.

More, some simulations have been performed to validate the proposed method in Matlab-simulink environment, by using SimPowerSystems toolbox. The simulation results shown in section III confirm the robustness, the rapidity of the OCF detection and the localization capability.

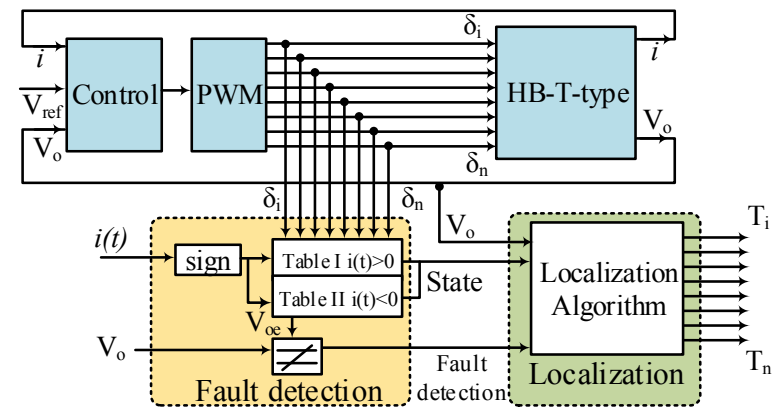

Fig. 3 Fault diagnosis principle for a T-type converter

Healthy conditions (State $2, \mathrm{i}(\mathrm{t})>0$ )
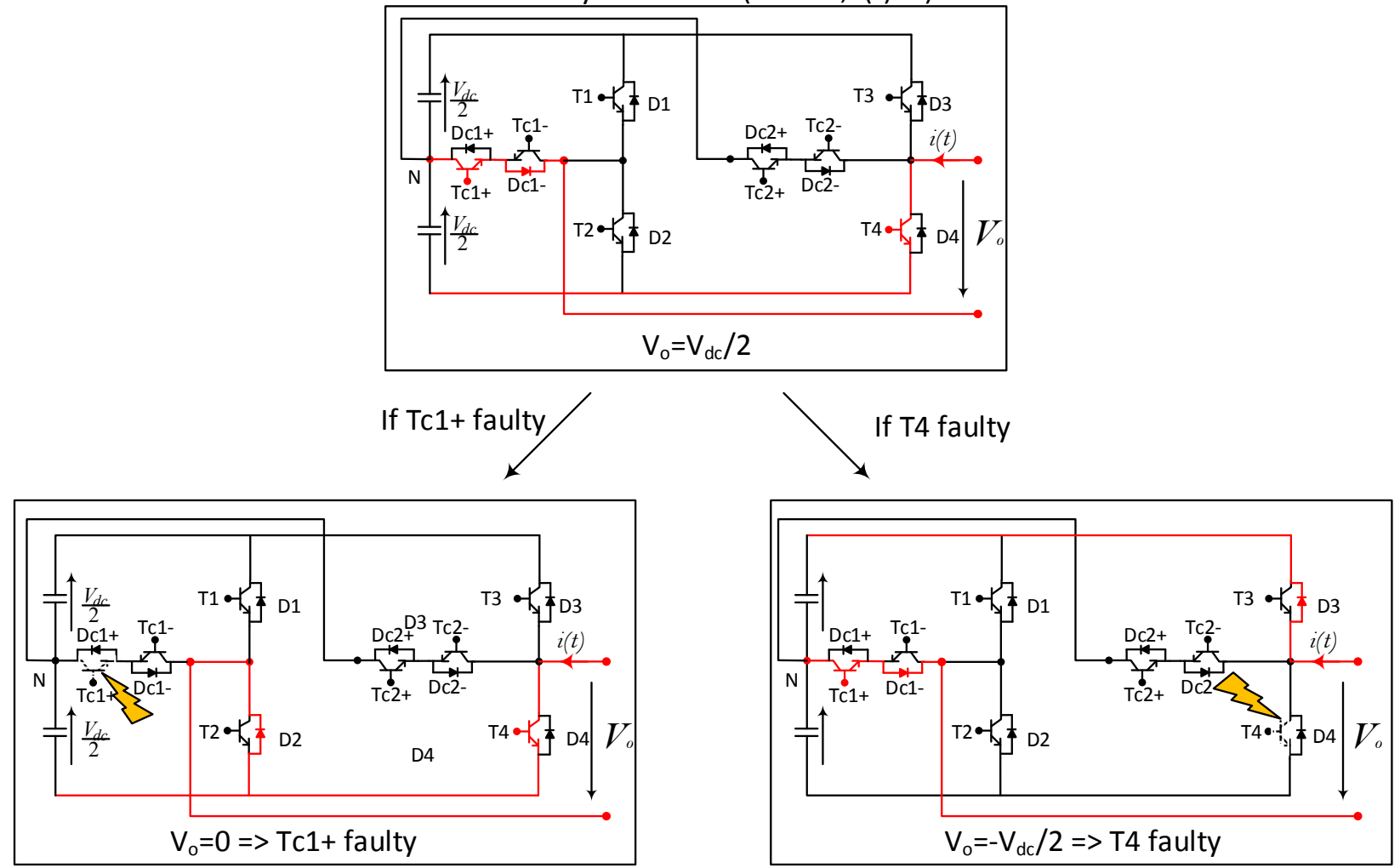

Fig. 4. Open switch fault diagnosis in State $2(\mathrm{i}(\mathrm{t})>0)$. 
Healthy conditions (State $3, \mathrm{i}(\mathrm{t})>0$
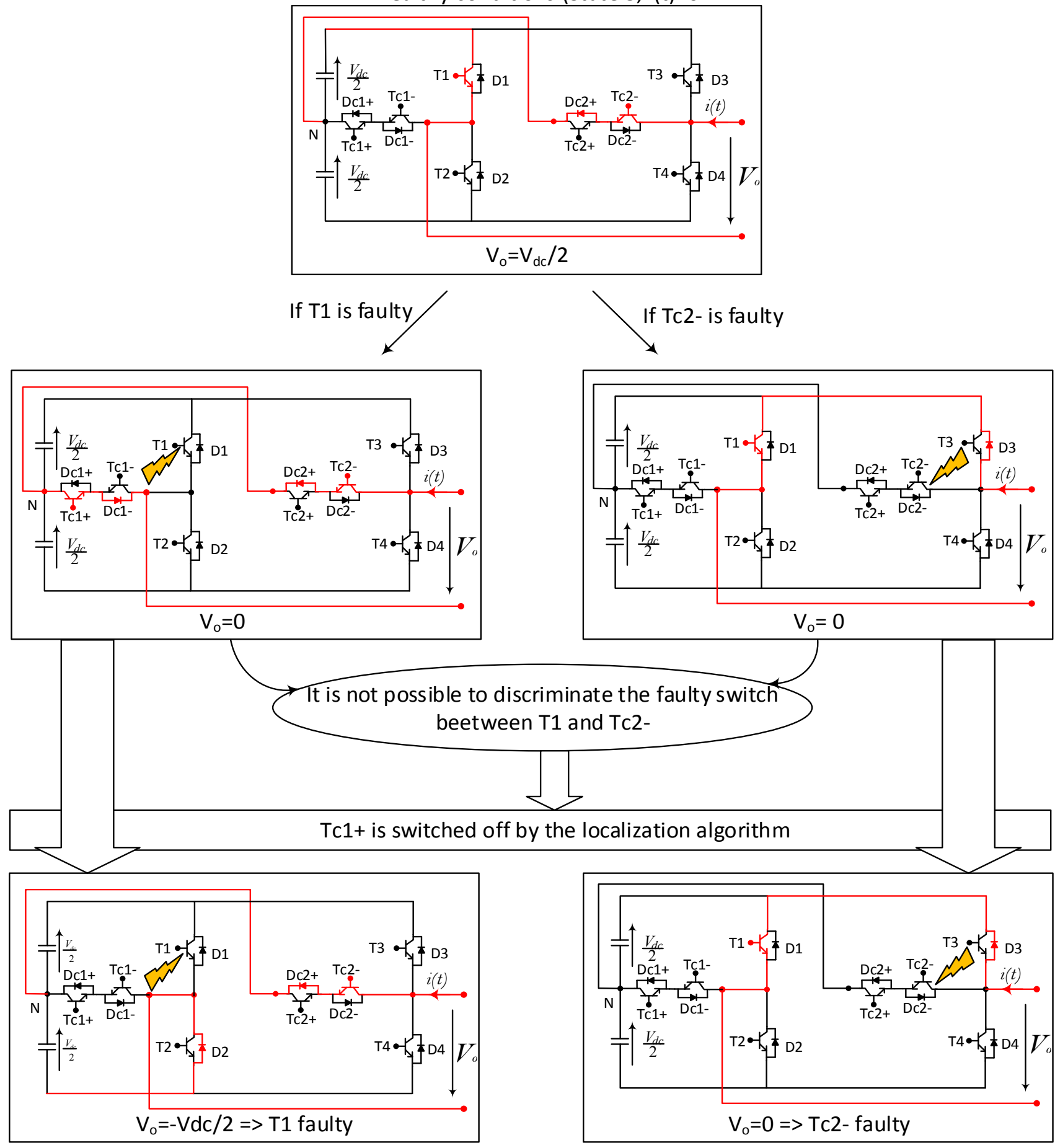

Fig 5. Open switch fault diagnosis in State 3.

\section{PRINCIPLE OF THE FAULT DIAGNOSIS METHOD}

Fig. 3 shows the principle of the proposed fault diagnosis [13]. The converter is controlled by a classical carrier-based PWM [12]. Thus, the switching pattern ( $\delta i \ldots \delta n)$ is generated by the control system. By using the switching pattern and the Tables I and II, the actual state (Sx), passing components and estimated output voltage $\left(\mathrm{V}_{\text {oe }}\right)$ can be determined. In normal condition, the measured output voltage $V_{0}$ is equal to the estimated voltage $\left(\mathrm{V}_{\mathrm{oe}}\right)$. Otherwise, in the case of an OCF, these voltage values $\left(\mathrm{V}_{\mathrm{o}}\right.$ and $\left.\mathrm{V}_{\mathrm{oe}}\right)$ are not equal.

The major problem in the studied five-level converters is the fault localization. The localization block (Fig. 3) identifies the faulty vertical or horizontal switch. Based on Tables I and II, several switches could be faulty in each state. To precise the fault location, the measured output voltage level is considered.

To clarify the localization principle, let us suppose an OCF 
detection when the converter operates in State $2(\mathrm{i}(\mathrm{t})>0)$ (Fig.4). In this case, according to Table 1 for the HB-T-Type topology, the faulty switch can be T4 (T23 or T24 for the HBNPP topology) or TC1+. In the HB-NPP topology case, the discrimination between T23 or T24 is not necessary to perform post-fault operation. By the same, if the declared fault was due to a fault occurrence on DC1-, considering $\mathrm{TC} 1+$ as faulty will lead to the same and suitable post fault operation. Here, the output voltage level will be equal to 0 if $\mathrm{TC} 1+$ is faulty (Fig.4). Otherwise, it will be equal to $\left(-\mathrm{V}_{\mathrm{dc}} / 2\right)$ if $\mathrm{T} 4$ (T23 or T24 for the HB-NPP topology) is faulty (Fig.4). To clarify the previous explanations, the equivalent circuits and the associated current paths are presented in Fig.4, in heathly conditions and when $\mathrm{Tc} 1+$ or $\mathrm{T} 4$ is faulty.

TABLE III

DIAGNOSIS OF THE FAULTY SWITCH FOR $\mathrm{i}(\mathrm{t})>0$

\begin{tabular}{|c|c|c|c|}
\hline \multirow{2}{*}{ State } & \multirow{2}{*}{ Healthy conditions } & \multicolumn{2}{|l|}{ Faulty conditions } \\
\hline & & Voltage level & Faulty switch \\
\hline \multirow{2}{*}{1} & \multirow{2}{*}{$\mathrm{V}_{\mathrm{o}}=\mathrm{V}_{\mathrm{dc}}$} & $\mathrm{V}_{\mathrm{o}}=0$ & $\mathrm{~T} 4$ \\
\hline & & $\mathrm{V}_{\mathrm{o}}=\mathrm{V}_{\mathrm{dc}} / 2$ & $\mathrm{~T} 1$ \\
\hline \multirow{2}{*}{2} & \multirow{2}{*}{$\mathrm{V}_{\mathrm{o}}=\mathrm{V}_{\mathrm{dc}} / 2$} & $\mathrm{~V}_{\mathrm{o}}=0$ & Tc1+ \\
\hline & & $\mathrm{V}_{\mathrm{o}}=-\mathrm{V}_{\mathrm{dc}} / 2$ & $\mathrm{~T} 4$ \\
\hline \multirow{6}{*}{3} & \multirow{6}{*}{$\mathrm{V}_{\mathrm{o}}=\mathrm{V}_{\mathrm{dc}} / 2$} & $\mathrm{~V}_{\mathrm{o}}=0$ & \multirow{3}{*}{ Tc2- } \\
\hline & & $\mathrm{Tc} 1+$ is switched off & \\
\hline & & $\mathrm{V}_{\mathrm{o}}=0$ & \\
\hline & & $\mathrm{V}_{\mathrm{o}}=0$ & \multirow{3}{*}{ T1 } \\
\hline & & Tc1+ is switched off & \\
\hline & & $V_{\mathrm{o}}=-\mathrm{V}_{\mathrm{dc}} / 2$ & \\
\hline \multirow{6}{*}{4} & \multirow{6}{*}{$\mathrm{V}_{\mathrm{o}}=0$} & $\mathrm{~V}_{\mathrm{o}}=0$ & \multirow{3}{*}{ Tc2- } \\
\hline & & T1 is switched on & \\
\hline & & $\mathrm{V}_{\mathrm{o}}=0$ & \\
\hline & & $V_{o}=0$ & \multirow{3}{*}{ Tc1+ } \\
\hline & & T1 is switched on & \\
\hline & & $\mathrm{V}_{\mathrm{o}}=\mathrm{V}_{\mathrm{dc}} / 2$ & \\
\hline 5 & $\mathrm{~V}_{\mathrm{o}}=0$ & $\mathrm{~V}_{\mathrm{o}}=-\mathrm{V}_{\mathrm{dc}} / 2$ & $\mathrm{~T} 1$ \\
\hline 6 & $\mathrm{~V}_{\mathrm{o}}=0$ & $\mathrm{~V}_{\mathrm{o}}=-\mathrm{V}_{\mathrm{dc}}$ & $\mathrm{T} 4$ \\
\hline 7 & $\mathrm{~V}_{\mathrm{o}}=-\mathrm{V}_{\mathrm{dc}} / 2$ & $\mathrm{~V}_{\mathrm{o}}=-\mathrm{V}_{\mathrm{dc}}$ & Tc2- \\
\hline 8 & $\mathrm{~V}_{\mathrm{o}}=-\mathrm{V}_{\mathrm{dc}} / 2$ & $\mathrm{~V}_{\mathrm{o}}=-\mathrm{V}_{\mathrm{dc}}$ & Tc1+ \\
\hline
\end{tabular}

Nevertheless in some states, it is not possible to determine the faulty switch by only comparing the estimated and measured output voltages. For example, let us consider the State $3(\mathrm{i}(\mathrm{t})>0)$. Fig. 5 presents the current paths when T1 or Tc2- is faulty: in both cases, the output voltage Vo is equal to 0 and it is not possible to discriminate the faulty switch. In fact, even if the only passing switches in the State 3 are T1 and Tc2-, the switching order applied to Tc1+ by the PWM control is ' 1 '. In heathly conditions, Tc1+ is open, even if an order equal to ' 1 ' is applied to its driver ( $\mathrm{Tc} 1+$ reverse biased, Fig.5). However, when an OCF of in T1 occurs, Tc1+ is no more reverse biased and conducts the output load current. Notice that in the case of an OCF in Tc2-, the switch T1 remains reverse biased (Fig.5). Consequently, after switch fault detection $\left(\mathrm{V}_{\mathrm{oe}} \neq \mathrm{Vo}_{\mathrm{o}}\right.$ i.e $\left.\mathrm{V}_{\mathrm{o}} \neq \mathrm{V}_{\mathrm{dc}} / 2\right)$ the localization algorithm (Fig. 3) switches off $\mathrm{Tc1}+$ which results in a new output voltage value (Fig. 5). If the resulting value of $\mathrm{V}_{\mathrm{o}}$ is equal to $-\mathrm{V}_{\mathrm{dc}} / 2$, the faulty switch is $\mathrm{T} 1$; otherwise, $\mathrm{V}_{\mathrm{o}}$ remains equal to 0 and the faulty switch is Tc2-. If necessary, the same approach can be applied in the suited states to perform OCF diagnosis (For example, Sates 3 and 4 when $i(t)>0$ ). Table III summarizes the fault diagnosis for $\mathrm{i}(\mathrm{t})>0$.

\section{SimULATION RESULTS}

To validate the performances of the proposed fault diagnosis method, some simulations are performed for a HB T-type converter feeding a $(\mathrm{R}, \mathrm{L})$ load with $\mathrm{R}=30 \Omega$ and $\mathrm{L}=10 \mathrm{mH}$ (Fig. 6). The $\mathrm{Vdc}$ is $1200 \mathrm{~V}$. The PWM switching frequency is $2 \mathrm{kHz}$. The simulations are realized in Matlab/Simulink environment by using SymPowerSystem library. The following simulation results are presented in two State cases, when an OCF occurs in the State 2 (subsection A) and when an OCF occurs in the State 3 (subsection B), as discussed in section II. Two OCF cases in State 2 are presented in the next subsection: the first case is an OCF of $\mathrm{Tc} 1+$ and the second one is an OCF of T4. In subsection B, we discuss the OCF diagnosis in State 4: first when T1 is faulty and secondly when Tc2- is faulty. The same validation by simulation has been performed for all other states.

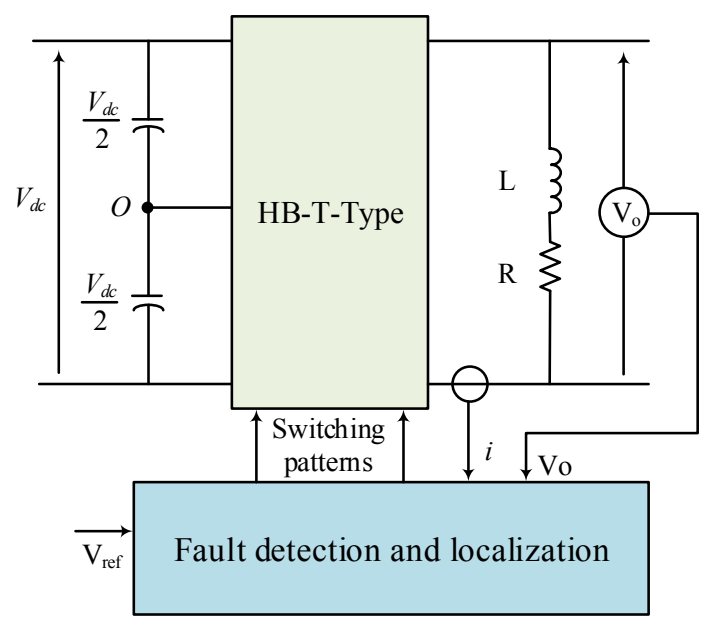

Fig. 6 HB-T-Type connected to a (R, L) load.

\section{A. Fault in State 2}

Fig 7. shows the simulation results when an OCF is occurred in Tc1+. To generate the OCF, the switching pattern of Tc1+ is forced to ' 0 ' by using the signal "Fault generation" (Fig 7). This signal modifies the control order applied to Tc1+, by forcing it to '0' when "fault generation" is switched to ' 1 '. By this way, at the time $t=6.1 \mathrm{~ms}$, an OCF is generated on Tc1+.

A zoom around the fault occurrence is provided in Fig. 8 in order to give more details on fault diagnosis. When the fault is occurred at $\mathrm{t}=6.1 \mathrm{~ms}$, Tc1+ is off. Therefore, until $\mathrm{t}=6.46 \mathrm{~ms}$, the values of $\mathrm{V}_{\mathrm{oe}}$ and $\mathrm{V}_{\mathrm{o}}$ are equal because $\mathrm{Tc} 1+$ is not switched on to generate the output voltage level. Thus, the OCF cannot be detected. At $\mathrm{t}=6.46 \mathrm{~ms}$, the command of Tc1+ switches to '1', but the switch remains off because of the generated OCF. As a result, the values of $\mathrm{V}_{\mathrm{o}}$ and $\mathrm{V}_{\mathrm{oe}}$ become different; then the fault can be declared (signal "Fault detection in Fig 8). 

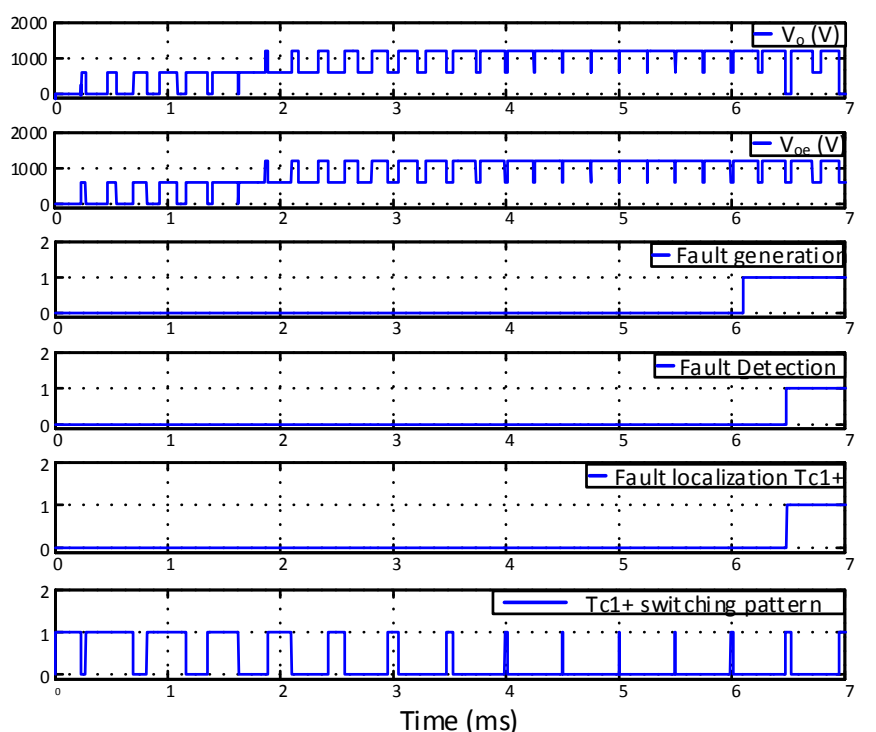

Fig. 7 Simulation results when $\mathrm{Tc} 1+$ is faulty $(\mathrm{OCF})$.
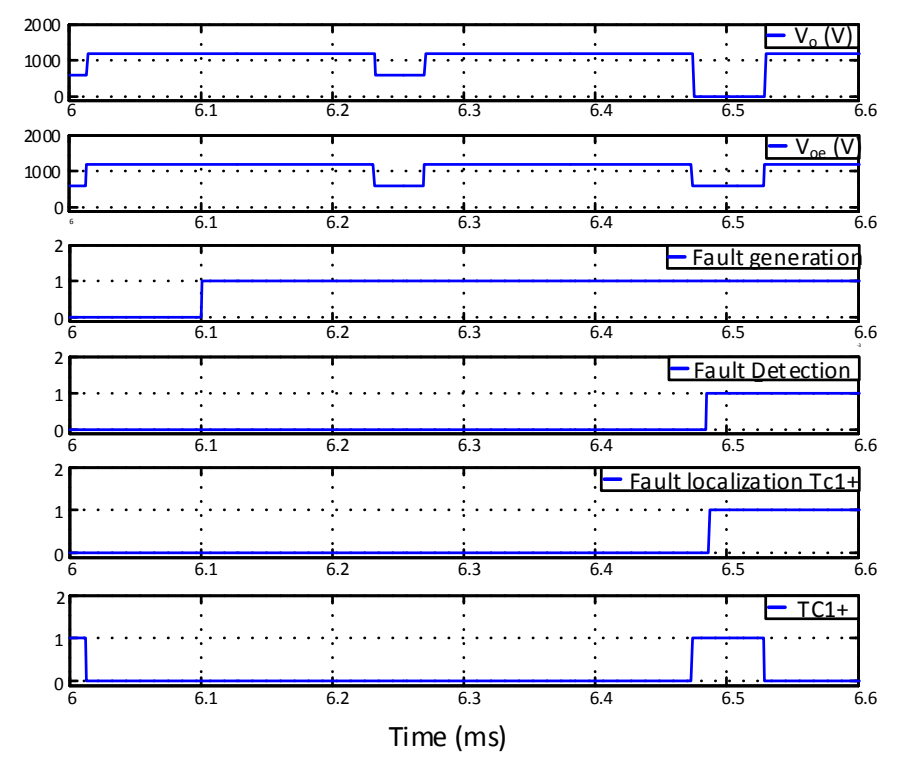

Fig. 8 Zoomed simulation results when Tc1+ is faulty (OCF).

After fault detection, fault localization must be performed. The proposed method not only declares the fault but also discriminates the faulty switch by considering the actual State during fault apparition, by using the switching pattern and Table I or Table II. In this case, the converter is in state S2 with $\mathrm{i}(\mathrm{t})>0$. Thus the faulty switch can be $\mathrm{T} 4$ or $\mathrm{TC} 1+$ and the output voltage should be $\mathrm{V}_{\mathrm{dc}} / 2$ (Heathly conditions). As it can be seen in Fig. 8, the output voltage is equal to ' 0 '. As mentioned in section II, the localization algorithm that observes the output voltage value can discriminate the faulty switch, here Tc1+.
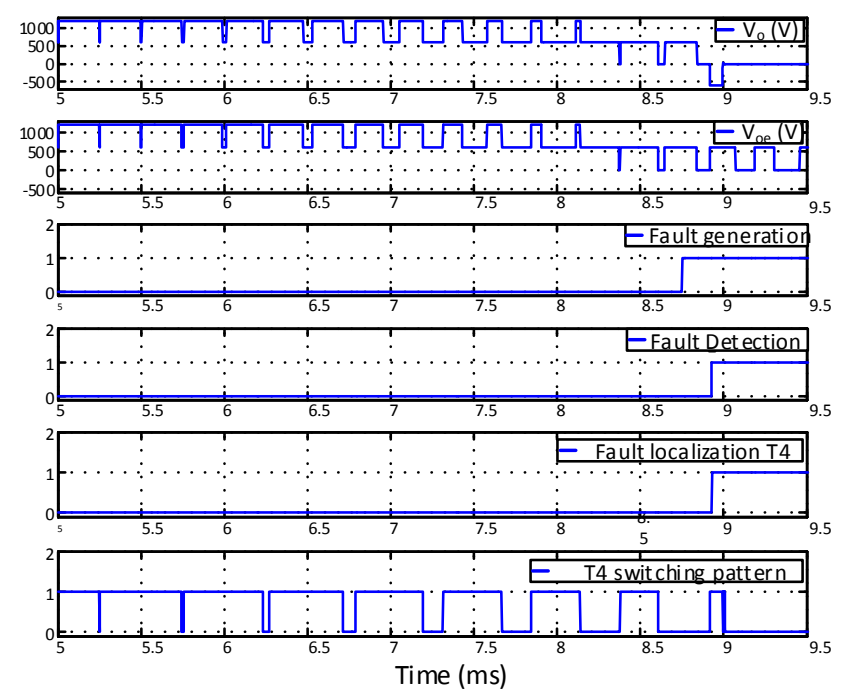

Fig. 9 Simulation results when T4 is faulty (OCF).

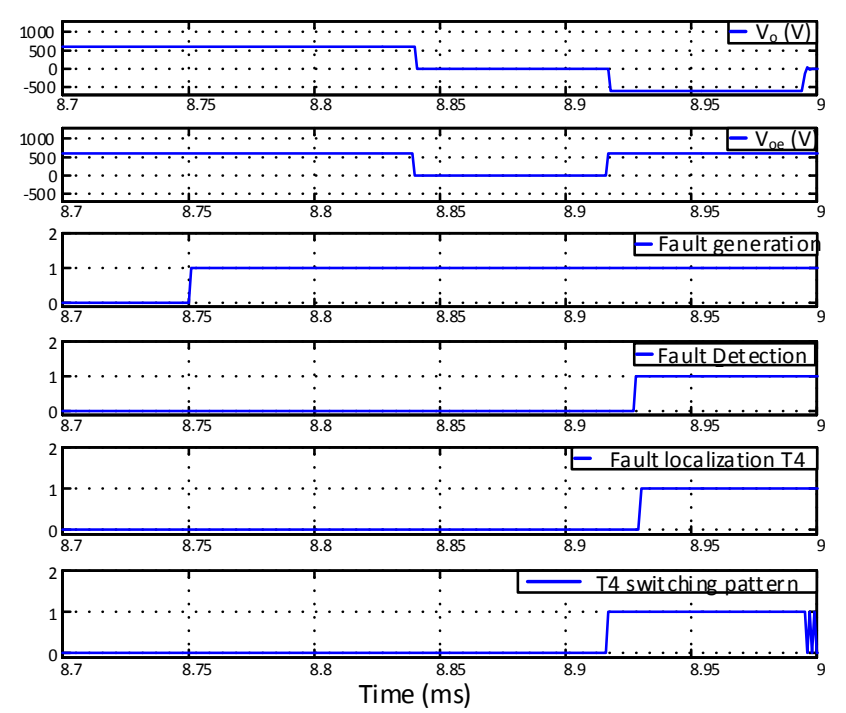

Fig. 10 Zoomed simulation results when T4 is faulty (OCF).

Fig. 9 shows the simulation results for an OCF in T4. In Fig. 10 which is a zoomed view of Fig. 9, after the fault occurrence, the OCF in T4 is generated by the signal "Fault generation". Nevertheless, this OCF cannot be detected while the command of T4 is ' 0 ' (T4 is off). When the command of T4 goes to ' 1 ', it remains off and then the output voltage of the $\mathrm{H}$-T-type converter becomes equal to $-\mathrm{V}_{\mathrm{dc}} / 2$ instead of $\mathrm{V}_{\mathrm{dc}} / 2$ (value of $\mathrm{V}_{\mathrm{oe}}$ ). By using Table I, the fault is declared when the converter is in state $\mathrm{S} 2$. In healthy conditions, in this state, $\mathrm{V}_{\mathrm{o}}$ should be equal to $\mathrm{V}_{\mathrm{dc}} / 2$. Therefore, an OCF can be declared. The fault localization is done by the localization algorithm and T4 is declared as the faulty switch.

\section{B. Fault in State 3}

In this subsection, an OCF in State 3 is considered. First, an OCF is artificially applied to T1 by using the suited signal "Fault generation" (See Fig. 11): consequently, at $t=8.7 \mathrm{~ms}$, an OCF is generated in T1. Figure 12 shows a zoom view of Fig. 11, for a short duration around the fault occurrence. As 
one can see in Fig. 12, when the OCF is artificially generated, the switching pattern of $\mathrm{T} 1$ is zero (time (1) in Fig. 12), thus the HB-NPP converter operates correctly. Consequently, no fault occurrence must be detected because $\mathrm{T} 1$ is normally open (area (2) in Fig. 12). At the time (3) in Fig. 12, the switching pattern of $\mathrm{T} 1$ becomes one and the output voltage $\mathrm{V}_{0}$ remains equal to zero instead of switching from zero to $\mathrm{Vdc} / 2$. At this time, an OCF is declared because $\mathrm{V}_{0}$ is different from $\mathrm{V}_{0 \mathrm{e}}$ (see (4) in the signal "Fault detection" in Fig. 12) but the faulty switch cannot be determined, as explained in Fig. 5. To discriminate the faulty switch between $\mathrm{T} 1$ and TC2-, TC1+ is switched to zero (see (5) in the signal "Fault detection" Fig. 12): thus, the output voltage $\mathrm{V}_{0}$ switches from zero to $(-\mathrm{Vdc} / 2)$ and the fault localization can be performed: $\mathrm{T} 1$ is declared as the faulty switch (see (6) in Fig. 12).

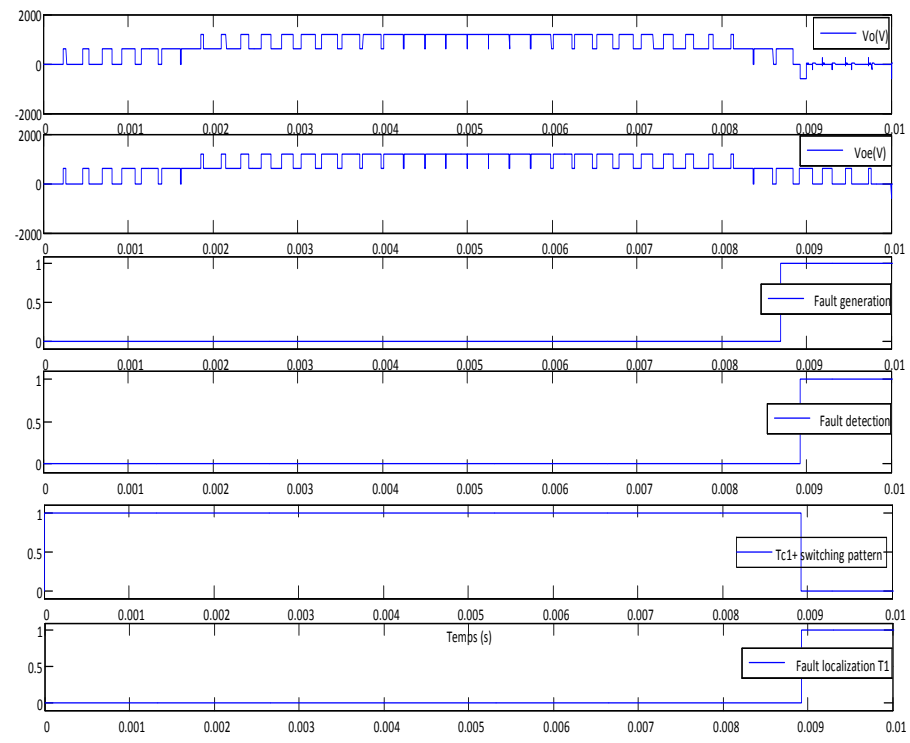

Fig.11: Simulation results when T1 is faulty (OCF in State 3).

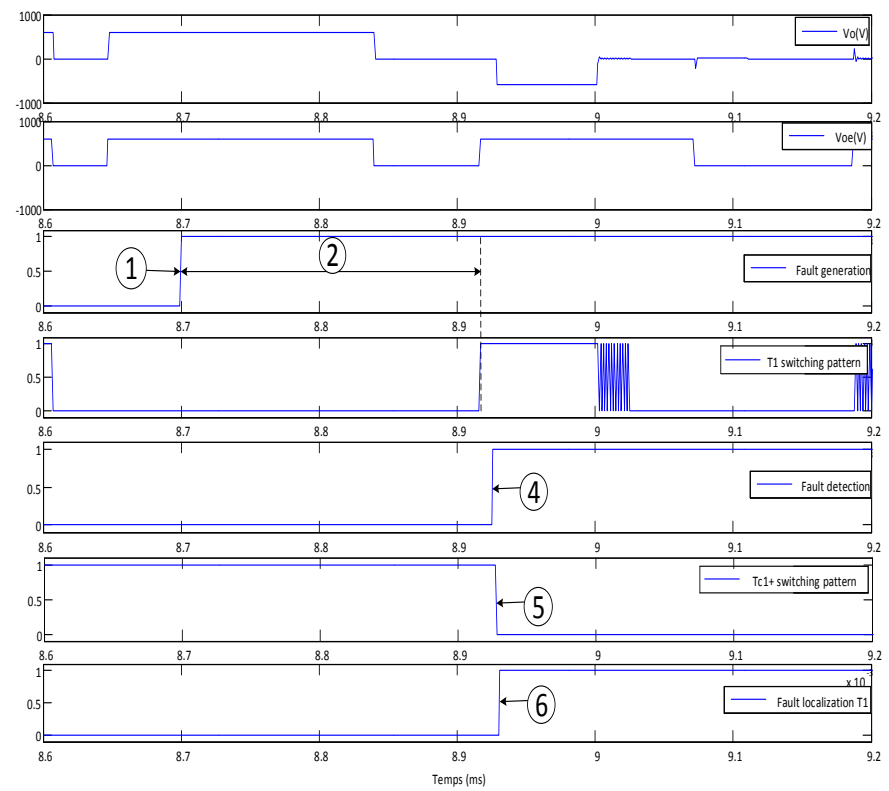

Fig.12: Zoomed Simulation results when T1 is faulty.
In the same spirit as the simulation previously discussed, an OCF is artificially applied to TC2- (See signal "Fault generation in Fig. 13): consequently, at $\mathrm{t}=8.96 \mathrm{~ms}$, an OCF is generated in TC2-. Figure 14 shows a zoom view of Fig. 13, for a short duration around the fault occurrence. As one can see in Fig. 14, when the OCF is artificially generated (time (1) in Fig. 14), the switching pattern of TC2- is one, thus the HBNPP converter do not operate correctly after the fault occurrence. The fault occurrence is quickly detected because the output voltage $\mathrm{V}_{0}$ becomes equal to zero instead of $\mathrm{Vdc} / 2$. (time (2) in Fig. 14). At this time (2), an OCF is declared because $\mathrm{V}_{0}$ is different from $\mathrm{V}_{0 \mathrm{e}}$ but the faulty switch cannot be determined, as explained in Fig. 5. To discriminate the faulty switch between $\mathrm{T} 1$ and TC2-, TC1+ is switched to zero (see (3) in the signal "Fault detection" in Fig. 14): thus, the output voltage $\mathrm{V}_{0}$ remains equal to zero and the fault localization can be performed: TC2- is declared as the faulty switch (see (4) in the signal "Fault detection" in Fig. 14).

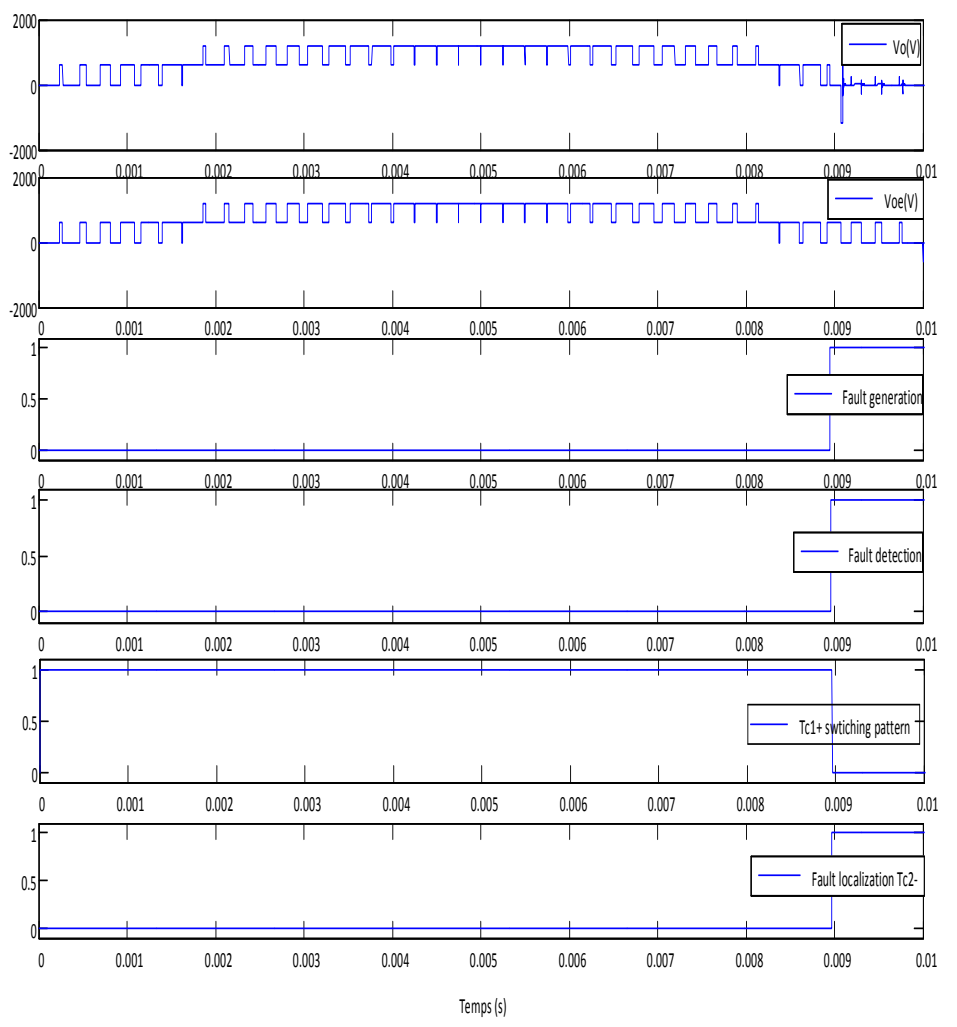

Fig.13 : Simulation results when Tc2- is faulty (OCF in state 3). 


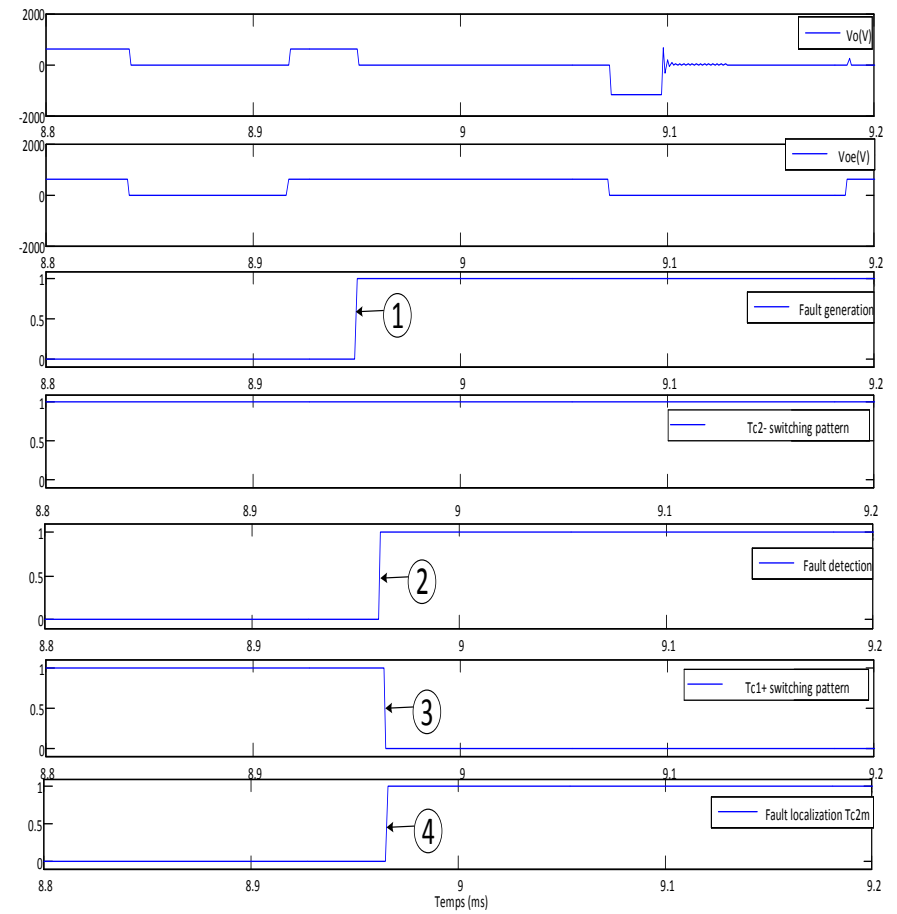

Fig. 14 : Zoomed Simulation results when Tc2- is faulty.

\section{CONCLUSION}

H-Bridge Neutral Point Piloted or T-type converters are increasingly being used in industrial applications. Generally, they are used in applications where continuity of service is mandatory. Furthermore, switch faults are the most common faults in power electronics converters. After a fault occurrence, in order to avoid its propagation in the whole system, a fast and robust fault diagnosis method must be implemented to perform the reconfiguration of the converter. Even if short-circuit faults are handled by the switches' drivers, this is not the case for open-switch faults. An openswitch fault diagnosis method for HB-NPP or T-type converters is proposed in this paper. This method is based on the switches states and on the output voltage level observation. The validity of the diagnosis is illustrated by simulations in some OCF cases.

\section{REFERENCES}

[1] B. Li, S. Shi, B. Wang, G. Wang, W. Wang, D, Xu,"Fault Diagnosis and Tolerant Control of Single IGBT Open-Circuit Failure in Modular Multilevel Converters", IEEE Transaction on Power Electronics, vol. 31, no. 4, pp. 3165-3176, April 2016.

[2] E. Jamshidpour, P. Poure and S. Saadate, "Photovoltaic Systems Reliability Improvement by Real-Time FPGA-Based Switch Failure Diagnosis and Fault-Tolerant DC-DC Converter", in IEEE Transactions on Industrial Electronics, vol. 62, no. 11, pp. 7247-7255, Nov. 2015.

[3] M. Aleenejad, H. Mahmoudi, P. Moamaei, R. Ahmadi, " A New FaultTolerant Strategy Based on a Modified Selective Harmonic Technique for Three-Phase Multilevel Converters With a Single Faulty Cell", IEEE Transaction on Power Electronics, vol. 31, no. 4, pp.3141-3150, April 2016.

[4] J. Xu, P, Zhao, C. Zhao," Reliability Analysis and Redundancy Configuration of MMC With Hybrid Submodule Topologies", IEEE Transaction on Power Electronics, vol. 31, no. 4, pp. 2720-2729, April 2016.
[5] Shuai Shao, P. W. Wheeler, J. C. Clare and A. J. Watson, "Fault Detection for Modular Multilevel Converters Based on Sliding Mode Observer", in IEEE Transactions on Power Electronics, vol. 28, no. 11, pp. 4867-4872, Nov. 2013.

[6] H. W. Sim, J. S. Lee and K. B. Lee, "A detection method for an openswitch fault in cascaded H-bridge multilevel inverters ", 2014 IEEE Energy Conversion Congress and Exposition (ECCE), Pittsburgh, PA, 2014, pp. 2101-2106.

[7] M. Shahbazi and M. Zolghadri, "Fast detection of open-switch fault in cascaded H-Bridge multilevel converter", Power Electronics, Drives Systems \& Technologies Conference (PEDSTC), 2015 6th, Tehran, 2015, pp. 538-543.

[8] Binbin Li, Shaolei Shi, Bo Wang, Gaolin Wang and Dianguo Xu, "Fault Diagnosis and Tolerant Control of Single IGBT Open-Circuit Failure in Modular Multilevel Converters", in IEEE Transactions on Power Electronics, vol. 31, no. 4, pp. 3165-3176, April 2016.

[9] F. Deng, Z. Chen, M. R. Khan and R. Zhu, "Fault Detection and Localization Method for Modular Multilevel Converters", in IEEE Transactions on Power Electronics, vol. 30, no. 5, pp. 2721-2732, May 2015.

[10] Qichen Yang, Jiangchao Qin and M. Saeedifard, "Analysis, Detection, and Location of Open-Switch Submodule Failures in a Modular Multilevel Converter", in IEEE Transactions on Power Delivery, vol. 31, no. 1, pp. 155-164, Feb. 2016.

[11] T. Wang, H. Xu, J. Han, E. Elbouchikhi and M. E. H. Benbouzid, "Cascaded H-Bridge Multilevel Inverter System Fault Diagnosis Using a PCA and Multiclass Relevance Vector Machine Approach", in IEEE Transactions on Power Electronics, vol. 30, no. 12, pp. 7006-7018, Dec. 2015.

[12] H. Shin, K. Lee, J. Choi, S. Seo and J. Lee, "Power loss comparison with different PWM methods for 3L-NPC inverter and 3L-T type inverter", 2014 International Power Electronics and Application Conference and Exposition, Shanghai, 2014, pp. 1322-1327.

[13] F. Becker, P. Poure, E. Jamshidpour, S. Saadate, "Open-Switch Fault Diagnosis for Five-Level H-Bridge Neutral Point Piloted or T-type Converters", 2016 IEEE 16th International Conference on Environment and Electrical Engineering (EEEIC), 7-10 June 2016, Florence, Italy.

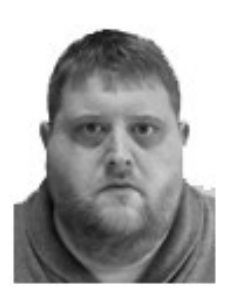

Florent Becker was born in France, in 1987. He received the M.S degree from Université de Nancy, Nancy, France, in 2011. He is currently working toward the Ph.D. degree in electrical engineering in the Faculty of Sciences and Technologies of Université de Lorraine, Nancy, France. His research interests are High Voltage Direct Current (HVDC), Modular Multi-Level Converter (MMC), renewable energy, and fault tolerant converters.

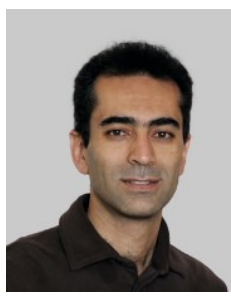

Ehsan Jamshidpour was born in Kermanshah, Iran, in 1975. He received the B.S. degree from University of Tabriz, Tabriz, Iran, in 1999, the M.S. degree from Sharif University of Technology, Tehran, Iran, in 2001 and Ph.D. in Electrical Engineering from University of Lorraine, Nancy, France, in 2014. From 2003 to 2010; he was an Assistant Professor in electrical engineering with the Institute for Energy and Hydro Technology, Kermanshah, Iran. He is currently with Laboratory Icube (UMR 7357) Université of Strasbourg, Illkirch, France. His research interests are Renewable energy, Power electronic converters and fault tolerant converters.

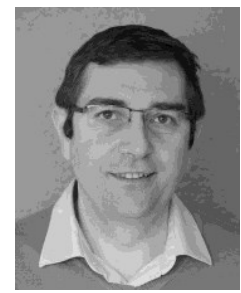

Philippe POURE was born in 1968. He received the Engineer Degree and Ph.D. Degree in Electrical Engineering from INPL-ENSEM-GREEN, France, in 1991 and 1995 respectively. From 1995 to 2004, he was an Associate Professor and worked at the University Louis Pasteur of Strasbourg, France, in the field of 
mixed-signal System-On-Chip for control and measurement in Electrical Engineering. Since September 2004, he joined the Université de Lorraine, Nancy - France and works on fault tolerant power systems, FPGA based real time applications and energy harvesting.

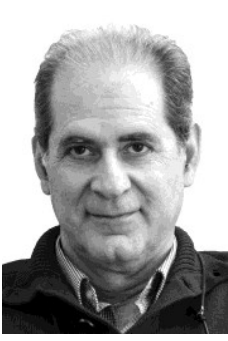

Shahrokh SAADATE received the diplôme d'ingenieur (1982), diplôme d'études approfondies (1982), Ph.D. degree in Electrical Engineering (1986) and habilitation à diriger les recherches scientifiques (1995) from ENSEM-INPL-GREEN, Nancy, France. Since 1996 he is full professor in University of Lorraine in Nancy.

He has been the head of GREEN Laboratory from 2009 to 2012.

His main research domain is power systems reliability, power quality and renewable energies. 